\title{
Activation of cAMP-Dependent Protein Kinase A in Prefrontal Cortex Impairs Working Memory Performance
}

\author{
Jane R. Taylor, ${ }^{1}$ Shari Birnbaum, ${ }^{2}$ Ravi Ubriani, ${ }^{2}$ and Amy F. T. Arnsten ${ }^{2}$ \\ ${ }^{1}$ Department of Psychiatry and 2 Section of Neurobiology, Yale University School of Medicine, New Haven, \\ Connecticut 06520-8001
}

Activation of the adenylyl cyclase-cAMP-protein kinase A (PKA) intracellular signaling cascade is necessary for long-term memory consolidation in brain regions such as the hippocampus. However, the role of the PKA cascade in the working memory functions of the prefrontal cortex (PFC) is unknown. The present study examined the effects of manipulating PKA activity in the PFC using the CAMP stereoisomers Sp-cAMPS and Rp-cAMPS, which activate and inhibit PKA, respectively. Animals received bilateral infusions of Sp-cAMPS and/or RpcAMPS into the PFC immediately before testing on the delayed alternation task, a test of spatial working memory that depends on the integrity of the PFC. Low doses of Sp-cAMPS $(0.21,2.1$, or $21 \mathrm{nmol} / 0.5 \mu \mathrm{l}$ ) produced a marked, dose-dependent impairment in working memory performance. The impairment produced by infusion of Sp-cAMPS $(21 \mathrm{nmol} / 0.5 \mu \mathrm{l})$ was fully reversed by co-infusion of Rp-cAMPS ( $21 \mathrm{nmol} / 0.5 \mu \mathrm{l})$, consistent with actions on PKA. Rp-cAMPS ( 21 or $42 \mathrm{nmol} / 0.5 \mu \mathrm{l}$ ) by itself had no effect on performance. These results indicate that activation of the PKA intracellular signaling cascade in the PFC impairs working memory performance. The current findings contrast with studies of long-term memory consolidation, in which inhibition of PKA with agents such as Rp-cAMPS impaired memory consolidation (Bernabeu et al., 1997; Bourtchouladze et al., 1998), whereas enhancement of the PKA pathway improved memory (Bernabeu et al., 1997; Barad et al., 1998). These results demonstrate that discrete cognitive processes subserved by different cortical regions are mediated by distinct intracellular mechanisms.

Key words: Sp-cAMPS; Rp-cAMPS; delayed alternation; rats; intracellular signals; PKA; memory
It is widely accepted that there are multiple types of memory processes subserved by interacting brain circuits. The hippocampal complex and related structures are important for the consolidation of long-term memories (Squire and Zola-Morgan, 1991), whereas the prefrontal cortex (PFC) is important for guiding behavior using working memories (Goldman-Rakic, 1987), i.e., memories that must be constantly updated. There has been extensive analysis of the second messenger mechanisms underlying long-term memory consolidation, but little is known about the intracellular pathways underlying working memory processes. Consolidation of long-term memories involves the activation of several intracellular signals, including the cAMP-dependent protein kinase A (PKA) second messenger system. The PKA pathway appears to be particularly important for the later phases of memory consolidation that require protein synthesis; there is little change in memory immediately after training, but changes are evident several hours or days later. For example, genetic (Abel et al., 1997) or pharmacological (Bernabeu et al., 1997; Bourtchouladze et al., 1998) inhibition of PKA can disrupt hippocampal long-term potentiation (LTP) and hippocampus-based long-term memory, whereas activation of the cAMP-PKA pathway can enhance LTP and facilitate long-term memory (Berna-

\footnotetext{
Received July 13, 1999; accepted July 14, 1999.

This work was supported by Public Health Service MERIT Award AG06036 and a National Alliance for Research on Schizophrenia and Depression Toulmin independent investigator award to A.F.T.A. We thank L. Ciavarella and T. White for expert technical assistance and Drs. Eric Nestler and Ronald Duman for support and inspiration.

Correspondence should be addressed to Amy F. T. Arnsten, Department of Psychiatry, Yale University School of Medicine, 333 Cedar Street, New Haven, CT 06520-8001.
}

Copyright (C) 1999 Society for Neuroscience 0270-6474/99/190001-05\$05.00/0 beu et al., 1997; Barad et al., 1998). The current study provided the first examination of the functional consequences of PKA activation on the working memory functions of the PFC. Because long-term memory and working memory are often modulated by very different neurochemical mechanisms, e.g., high levels of catecholamines or stress exposure can improve long-term memory but impair working memory (for review, see Arnsten, 1998), we hypothesized that the intracellular mechanisms governing working memory processes might also be fundamentally different from those subserving long-term memory changes. The present study examined the consequences of activating or inhibiting PKA in the rat PFC using two membrane-permeable stereoisomeric analogs of cAMP, Sp-cAMPS and Rp-cAMPS, which are commonly used to activate and inhibit PKA, respectively (Van Haastert et al., 1984; Surmeier et al., 1995; Punch et al., 1997; Bourtchouladze et al., 1998; Huang and Kandel, 1998; Self et al., 1998). Working memory was assessed by a spatial delayed alternation task in a $\mathrm{T}$ maze, the cognitive task most commonly used to investigate PFC function in rodents (Larsen and Divac, 1978).

This article is published in The Journal of Neuroscience, Rapid Communications Section, which publishes brief, peerreviewed papers online, not in print. Rapid Communications are posted online approximately one month earlier than they would appear if printed. They are listed in the Table of Contents of the next open issue of JNeurosci. Cite this article as: JNeurosci, 1999, 19:RC23 (1-5). The publication date is the date of posting online at www.jneurosci.org.

http://www.jneurosci.org/cgi/content/full/3454 
The results from this study indicate that intracellular regulation in the PFC is opposite from the hippocampus, because activation of the PKA pathway impairs, rather than improves, the working memory functions of the PFC.

\section{MATERIALS AND METHODS}

The methods used in this study were the same as those used by Zahrt et al. (1997) and Arnsten et al. (1999). The reader is referred to these publications if more lengthy descriptions of methods are needed. The use of animals in this research was approved by the Yale Animal Care and Use Committee.

Subjects. Male Sprague Dawley rats weighing 240-280 gm were purchased from Camm Research Institute (Wayne, NJ) or Taconic (Germantown, NY) and pair-housed in filter frame cages. The rats were kept on a $12 \mathrm{hr}$ light/dark cycle, and the experiments were conducted during the light phase. The animals were fed a diet of autoclaved Purina (St. Louis, MO) rat chow (17 gm/d per rat) immediately after behavioral testing. Water was available ad libitum. Rats were weighed weekly and achieved weights of $\sim 400 \mathrm{gm}$. Food rewards during cognitive testing were highly palatable miniature chocolate chips, thus minimizing the need for dietary regulation. Rats were assigned a single experimenter who handled them extensively before behavioral testing.

Delayed alternation. The delayed alternation task was selected for comparison to previous studies of (1) PFC catecholamine depletion (Bubser and Schmidt, 1990), (2) stress (Murphy et al., 1996a), and (3) intra-PFC D1 (Zahrt et al., 1997) or $\alpha$-1 adrenergic (Arnsten et al., 1999) agonist infusions, which similarly used this paradigm. The delayed alternation task uses a number of processes associated with PFC function: (1) spatial working memory (Goldman-Rakic, 1987), (2) egocentric spatial processing (Kesner et al., 1989), and (3) inhibition of proactive interference and inappropriate motor responses (Mishkin, 1964; Kolb, 1990) and is thus a good task for detecting altered PFC function. Rats were initially habituated to a $\mathrm{T}$ maze (dimensions, $90 \times 65 \mathrm{~cm}$ ) for $5 \mathrm{~d}$ until they were readily eating chocolate chips placed in the food wells at the end of each arm. After habituation, rats were trained on the delayed alternation task. On the first trial, animals were rewarded for entering either arm. Thereafter, for a total of 10 trials per session, rats were rewarded only if they entered the maze arm that was not previously chosen. Between trials the choice point was wiped with alcohol to remove any olfactory clues. The delay between trials was $0 \mathrm{sec}$ during initial training and was raised in 5 sec intervals as needed to maintain performance at $\sim 70-80 \%$ correct. After approximately five training sessions, animals underwent surgery to implant indwelling guide cannulae directed at the PFC. Testing on the delayed alternation task was reinstated only after the implant had healed completely, $\sim 2$ weeks after surgery. Animals were adapted to the infusion procedure, and infusions were administered only when baseline performance was stable. Delays averaged $19.4 \pm 9.8 \mathrm{sec}$ for the first inf usion and were gradually raised over the 6 month study to an average of $46.3 \pm 11.1 \mathrm{sec}$ to maintain baseline performance at $70-80 \%$ correct. This baseline level of performance allowed for the detection of either improvement or impairment with drug administration.

The response to drug was further characterized by analyzing the pattern of errors on the delayed alternation task. A perseverative pattern of response is consistent with dysfunction of the PFC (Kolb, 1990). Perseverative responding was assessed by measuring the greatest number of consecutive entries into a single arm. Run times were measured to detect any changes in motor performance, and rats were observed for any gross changes in behavior.

Cannula implantation. After training on the delayed alternation task, rats underwent stereotaxic implantation of chronic guide cannulae. Surgery was performed under ketamine $(80 \mathrm{mg} / \mathrm{kg})$ and xylazine $(10 \mathrm{mg} / \mathrm{kg})$ anesthesia using aseptic methods. Guide cannulae consisted of $9.0 \mathrm{~mm}$ of 23 gauge stainless steel directed immediately dorsal to the medial PFC [prelimbic PFC; stereotaxic coordinates: anterioposterior, $+3.2 \mathrm{~mm}$; mediolateral, $\pm 0.75 \mathrm{~mm}$; dorsoventral (DV), -1.7 to $-3.0 \mathrm{~mm}$ ]. Cannulae (Plastics Products) were affixed to the skull using dental cement secured with sterile stainless steel screws. A sterile stylet was screwed into place in each guide cannula to prevent occlusion. Stylets were changed on a regular basis to maintain patency.

Great care was taken to minimize pain and infection postoperatively to decrease stress to the animal. Rats were monitored on a daily basis for signs of distress or infection and were acutely treated with Buprenex $(0.01 \mathrm{mg} / \mathrm{kg})$ to decrease pain. Rats were housed singly after surgery.

Infusion procedure. Animals were initially adapted to a mock infusion protocol to minimize any stress associated with the procedure. Rats were gently restrained while the stylets were removed and replaced with 30 gauge sterile infusion needles that extended to $-4.5 \mathrm{~mm}$ DV below the skull. Bilateral infusions were driven by a Harvard Apparatus (Holliston, MA) syringe pump set at a flow rate of $0.225 \mu \mathrm{l} / \mathrm{min}$ using $25 \mu \mathrm{l}$ Hamilton syringes for an inf usion time of $2 \mathrm{~min} 13 \mathrm{sec}$. Needles remained in place for $2 \mathrm{~min}$ after the completion of the infusion. Stylets were inserted back into the cannulae, and behavioral testing began immediately after the infusion procedure.

Drug treatment. The research used a within-subjects design; thus, all animals received all treatments within an experiment. Drug treatments were administered in a counterbalanced order with at least 1 week between each infusion. In Experiment 1, animals received four doses of Sp-cAMPS $(0,0.21,2.1$, or $21 \mathrm{nmol} / 0.5 \mu \mathrm{l})$. In Experiment 2, animals received four treatments: vehicle + vehicle $(0.5 \mu 1)$; vehicle $+\mathrm{Sp}-$ cAMPS (lowest effective dose, $0.5 \mu \mathrm{l}$ ); vehicle + Rp-cAMPS (21 nmol, $0.5 \mu \mathrm{l})$; or Sp-cAMPS + Rp-cAMPS $(21 \mathrm{nmol}, 0.5 \mu \mathrm{l})$. In Experiment 3 , a higher dose of Rp-cAMPS (42 nmol, $0.5 \mu \mathrm{l}$ ) was compared with vehicle $(0.5 \mu \mathrm{l})$. The experimenter testing the animal was unaware of the drug treatment conditions.

Sp-cAMPS and Rp-cAMPS were purchased from Research Biochemicals (Natick, MA). Sp-cAMPS and Rp-cAMPS were dissolved in sterile PBS as described by Punch et al. (1997). For example, the $21 \mathrm{nmol}$ dosage was produced by dissolving $1 \mathrm{mg}$ of Sp-cAMPS or Rp-cAMPS in $54 \mu \mathrm{l}$ of PBS to produce a $42 \mathrm{~mm}$ concentration; $0.5 \mu \mathrm{l}$ of this solution was infused into each side of the PFC.

Histology. At the completion of the experiment, rats were killed by overdose with barbiturate. Dye was infused into the cannulae before death in a subset of animals to aid visualization of cannula placement. Brains were stored in formalin, sectioned, and analyzed for histological verification of cannulae placement. All rats had correctly placed cannulae. The location of the ventral tips of the guide cannula are illustrated in Figure 1.

Data analysis. Given within-subjects comparisons, data were analyzed with repeated measures designs. In Experiment 1, the effects of increasing dose of Sp-cAMPS were evaluated using a one-way repeated measures ANOVA with planned comparisons (test of effects; Systat, Evanston, IL). In Experiment 2, the effects of Rp-cAMPS co-infusion on the Sp-cAMPS response were evaluated using a two-way repeated analysis (2-ANOVA-R) with planned comparisons (user-defined contrasts; Systat). Paired comparisons in Experiment 3 were evaluated using a paired $t$ test, T-dependent (T-dep). Statistical analyses were performed on a Macintosh G3 computer using Systat software.

\section{RESULTS \\ Experiment 1: effects of intra-PFC infusions of Sp- cAMPS on delayed alternation performance}

The first experiment $(n=7)$ examined the effects of activating PKA on delayed alternation performance by infusing Sp-cAMPS $(0,0.21,2.1$, or $21 \mathrm{nmol} / 0.5 \mu \mathrm{l})$ into each side of the PFC. The results are shown in Figure $2 A$. Sp-cAMPS produced a marked, dose-related impairment in delayed alternation performance (one way ANOVA with repeated measures, significant effect of Sp-cAMPS dose: $\left.F_{(3,18)}=11.49 ; p=0.00019\right)$. Only the $21 \mathrm{nmol}$ dose was significantly different from vehicle (user-defined contrasts: vehicle vs $0.21 \mathrm{nmol}, F_{(1,6)}=0.48 ; p=0.52$; vehicle vs 2.1 nmol, $F_{(1,6)}=1.24 ; p=0.31$; vehicle vs $21 \mathrm{nmol}, F_{(1,6)}=140.245$; $p=0.00002)$. Consistent with PFC dysfunction, $21 \mathrm{nmol} \mathrm{Sp-}$ cAMPS infusions tended to produce a more perseverative pattern of responding (greatest number of consecutive entries into an arm after vehicle vs $21 \mathrm{nmol}$ Sp-cAMPS infusions. $2.8 \pm 0.4$ vs $4.4 \pm 1.0$ entries; $\mathrm{T}$-dep $=2.67 ; \mathrm{df}=4 ; p=0.056)$. Rats infused with $21 \mathrm{nmol}$ Sp-cAMPS also tended to freeze and have slower response times, although this effect was highly variable (response times after vehicle vs $21 \mathrm{nmol} \mathrm{Sp-cAMPS}$ infusions, $4.4 \pm 1.1 \mathrm{vs}$ $19.5 \pm 10.1 \mathrm{sec} ; \mathrm{T}$-dep $=1.6 ; \mathrm{df}=4 ; p=0.18)$ and not correlated with accuracy of response $(p=0.3)$. Performance returned to normal levels of responding the following testing day (70.0 \pm $11.2 \%$ correct). 


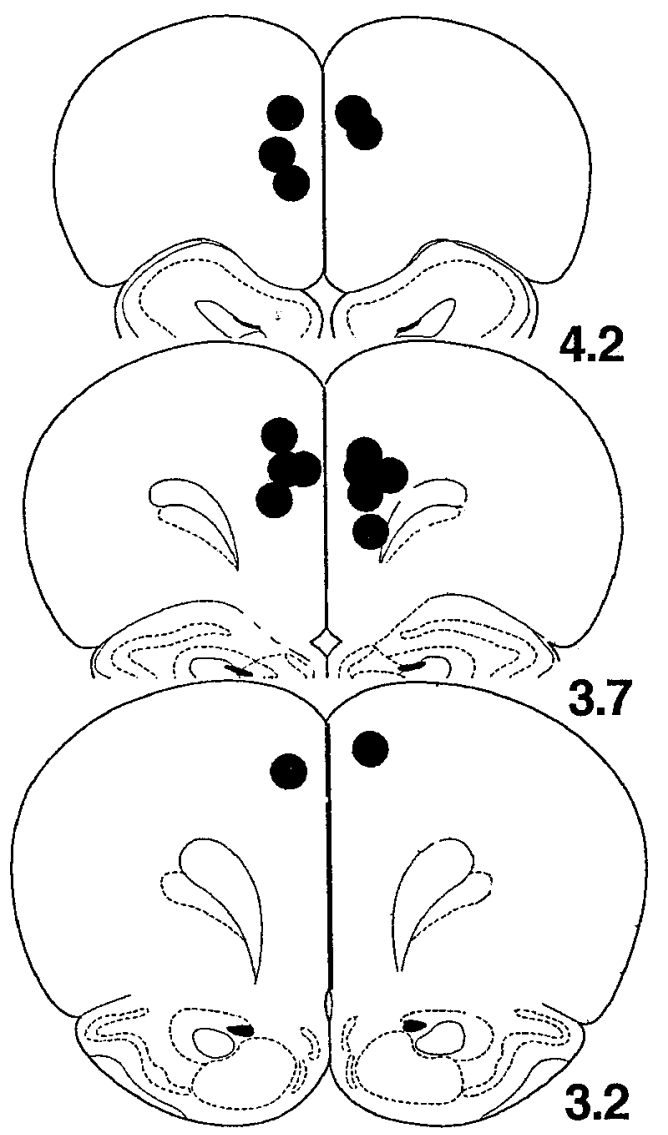

Figure 1. Schematic illustration of the ventral tips of the guide cannula directed above the rat PFC for all animals in this study (ventral tip represented by a circle). Levels represent 3.2, 3.7, and $4.2 \mathrm{~mm}$ anterior to Bregma.

A pilot experiment in two animals with more superficially placed guide cannula (DV, $-1.7 \mathrm{~mm}$ ) showed that shallow infusions of $21 \mathrm{nmol} / 0.5 \mu \mathrm{l} \mathrm{Sp-cAMPS}$ into the shoulder cortex dorsal to the PFC had no effect on delayed alternation performance ( $90 \%$ correct), whereas the deeper infusions into the PFC were effective in impairing performance ( $40 \%$ correct). Further control infusions into brain areas dorsal, lateral, and ventral to the PFC will be needed to verify anatomical specificity of the SpcAMPS response.

\section{Experiment 2: Rp-cAMPS reversal of the Sp-cAMPS response}

To test whether the detrimental effects of Sp-cAMPS resulted from actions on PKA, the Sp-cAMPS response was challenged with co-infusion of Rp-cAMPS, the isomer that inhibits PKA activity. Animals $(n=5)$ were administered four different treatments in counterbalanced order: vehicle, Sp-cAMPS (lowest effective dose for each rat; see legend to Fig. 2B), $21 \mathrm{nmol}$ of Rp-cAMPS, and Sp-cAMPS plus $21 \mathrm{nmol}$ of Rp-cAMPS. The results of this experiment can be seen in Figure $2 B$. Co-infusion of Rp-cAMPS completely reversed the detrimental effects of Sp-cAMPS (2-ANOVA-R: main effect of Sp, $F_{(1,4)}=15.07 ; p=$ 0.018 ; main effect of Rp, $F_{(1,4)}=53.3 ; p=0.002 ; \mathrm{Sp} \times \mathrm{Rp}$ interaction, $F_{(1,4)}=56.0 ; p=0.002$; user-defined contrasts: vehicle vs Sp, $F_{(1,4)}=42.67 ; p=0.003 ; \mathrm{Sp}$ vs $\mathrm{Sp}+\mathrm{Rp}, F_{(1,4)}=192.67$; $p<0.0001$; vehicle vs $\left.\mathrm{Sp}+\mathrm{Rp}, F_{(1,4)}=0.29 ; p=0.62\right)$. The 21 nmol dose of Rp-cAMPS by itself had no significant effect on
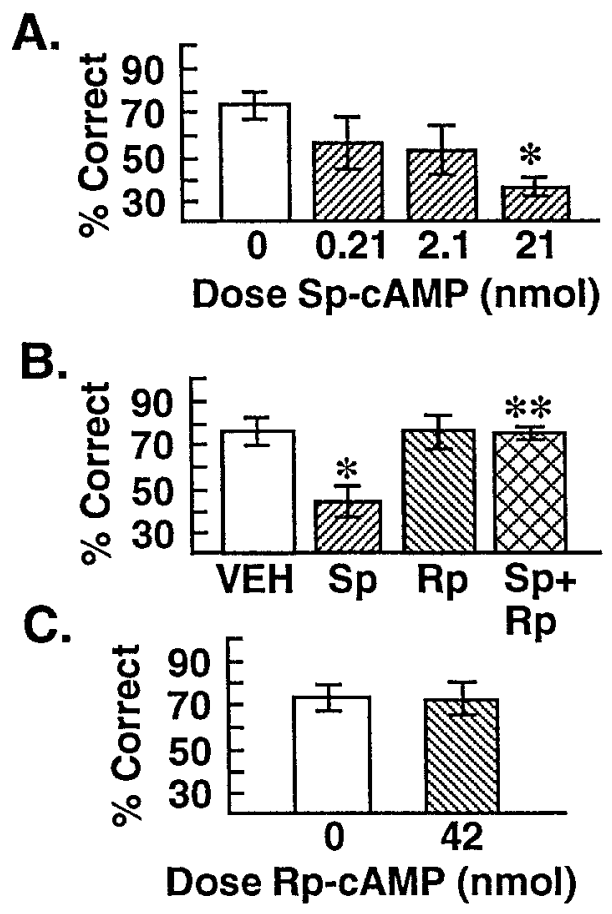

Figure 2. Effects of bilateral intra-PFC infusions of the PKA activator Sp-cAMPS and the PKA inhibitor Rp-cAMPS on delayed alternation performance in rats. $A$, Sp-cAMPS (0, 0.21, 2.1, and $21 \mathrm{nmol} / 0.5 \mu \mathrm{l})$ produced a dose-related impairment of delayed alternation performance. Results represent mean \pm SEM percent correct; $n=7$. ${ }^{*}$ Significantly different from performance after vehicle infusion. $B$, The detrimental effects of Sp-cAMPS were reversed by co-infusion of Rp-cAMPS (21 $\mathrm{nmol} / 0.5 \mu \mathrm{l})$. The dose of Sp-cAMPS was the lowest dose that substantially impaired performance $(n=3,21 \mathrm{nmol} ; n=1,2.1 \mathrm{nmol} ; n=1,0.21$ nmol). Rp-cAMPS ( $21 \mathrm{nmol} / 0.5 \mu \mathrm{l})$ had no effect on performance by itself. Results represent mean \pm SEM percent correct; $n=5$. *Significantly different from performance after vehicle infusion; **significantly different from performance after Sp-cAMPS infusion. $V E H$, vehicle; $S p$, Sp-cAMPS; $R p$, Rp-cAMPS. $C$, Intra-PFC infusions of Rp-cAMPS (42 $\mathrm{nmol} / 0.5 \mu \mathrm{l})$ had no effect on delayed alternation performance. Results represent mean $\pm \mathrm{SEM}$ percent correct; $n=5$.

performance compared with vehicle control (user defined contrasts: vehicle vs $21 \mathrm{nmol} R \mathrm{Rp}, F_{(1,4)}=2.25 ; p=0.21$ ).

\section{Experiment 3: effects of a higher dose of Rp-cAMPS on delayed alternation performance}

It is possible that the $21 \mathrm{nmol}$ dose of Rp-cAMPS had no effect on performance by itself because of insufficient dosage. This hypothesis was tested by inf using a higher dose of Rp-cAMPS (42 $\mathrm{nmol} / 0.5 \mu \mathrm{l}$ ) into the PFC. The $42 \mathrm{nmol}$ dose has previously been shown to inhibit PKA activity and signs of opioid withdrawal when infused into the nucleus locus coeruleus of opiate-addicted rats (Punch et al., 1997) and to reduce cocaine self-administration when infused into the nucleus accumbens (Self et al., 1998). The results of the current experiment can be seen in Figure $2 C$. The 42 nmol dose of Rp-cAMPS had no effect on delayed alternation performance compared with vehicle control infusions (vehicle, $74 \pm 5.7 \%$ correct; $42 \mathrm{nmol} \mathrm{Rp}, 72 \pm 7.4 \% ; n=5$; T-dep, $p>0.8)$.

\section{DISCUSSION}

The present study revealed that infusions of the PKA activator Sp-cAMPS into the rodent PFC markedly impaired performance of the delayed alternation task. It is noteworthy that performance 
after $21 \mathrm{nmol}$ Sp-cAMPS treatment produced near chance levels of response for a two-choice task ( $\sim 40 \%$ correct), and that this effect was comparable in magnitude with the effects of acute ablation of the PFC (Brito et al., 1982). The impairment induced by Sp-cAMPS was reversed by the PKA inhibitor Rp-cAMPS (21nmol). Importantly, neither dose of Rp-cAMPS (21 or 42 nmol) altered performance on its own. Thus, the reversal of the Sp-cAMPS response could not result from additive effects of the two treatments. This response profile also suggests that the impairment observed after Sp-cAMPS treatment did not result from nonspecific disruption of the PKA cascade, because Rp-cAMPS would have been equally disruptive if this were true. The data also argue against actions at adenosine receptors or cAMP-gated channels, which can be stimulated by adenosine compounds such as Sp-cAMPS and Rp-cAMPS (Finn et al., 1996). However, Spand Rp-cAMPS would be expected to have similar effects on behavior if they were acting through these mechanisms (Finn et al., 1996). Rather, the current results are consistent with competing effects of Sp-cAMPS versus Rp-cAMPS on PKA activity. More research is needed with additional agents that increase activity of the CAMP-PKA pathway to reinforce this interpretation.

There are several possible explanations for the lack of effect of Rp-cAMPS by itself on delayed alternation performance. One unlikely possibility is that Rp-cAMPS may not have penetrated the cells in the PFC sufficiently to inhibit PKA activity. However, the 42 nmol dose has been effective in other brain regions (Punch et al., 1997; Self et al., 1998), and the $21 \mathrm{nmol}$ dose was fully effective in reversing the Sp-cAMPS response in the present study. These data indicate that Rp-cAMPS was capable of permeating the cell membrane and inhibiting PKA activity in this study. Alternatively, the PKA cascade may not be sufficiently active in PFC under nonstress conditions to visibly influence behavior, or the Rp-cAMPS doses used in the current study, although effective in other brain regions, may not have been appropriate for altering PFC function. More research is needed with a wider Rp-cAMPS dose range and with additional agents to thoroughly examine the consequences of PKA inhibition on PFC function. We are currently conducting an extensive study testing a wide range of Rp-cAMPS doses (0.021-84 nmol). To date, our preliminary results have shown no effect on performance with these additional doses.

\section{Possible relevance of PKA activation to stress-induced PFC dysfunction}

Activation of the PKA pathway may contribute to the deficits in PFC function observed during exposure to mild, uncontrollable stress. Exposure to stress impairs performance of spatial working memory tasks such as delayed alternation and delayed response in rats and monkeys, respectively (Murphy et al., 1996a; Arnsten and Goldman-Rakic, 1998). In contrast, stress has no effect on control tasks such as spatial or visual pattern discrimination that have similar motor and motivational demands but do not depend on PFC function (Murphy et al., 1996a; Arnsten and GoldmanRakic, 1998). This pattern of results has indicated that stress does not produce nonspecific performance deficits but rather impairs the cognitive functions of the PFC. Stress-induced cognitive deficits arise, at least in part, from high levels of dopamine D1 receptor stimulation in the PFC (Murphy et al., 1996a; Arnsten and Goldman-Rakic, 1998), a receptor family that is positively coupled to the PKA pathway (Duman and Nestler, 1995). Expo- sure to mild stress (Murphy et al., 1996a) or intra-PFC infusions of either a D1 receptor agonist (Zahrt et al., 1997) or Sp-cAMPS (present study) impair delayed alternation performance and produced a mildly perseverative pattern of response. D1 receptor stimulation has also been shown to decrease working memory at the cellular level as measured by delay-related activity of PFC pyramidal neurons (Williams and Goldman-Rakic, 1995). High levels of D1 receptor stimulation in the PFC may impair working memory by diminishing the calcium currents that convey signals from the distal dendrites to the soma (Yang and Seamans, 1996; Zahrt et al., 1997). This process is likely mediated by activation of PKA (Surmeier et al., 1995). Conversely, $\alpha$-2 adrenergic agonists can inhibit the cAMP-PKA pathway via $\mathrm{G}_{\mathrm{i}}$, and these agents are very effective in reversing stress-induced cognitive deficits (Birnbaum and Arnsten, 1996; Murphy et al., 1996b; Arnsten and Goldman-Rakic, 1998). Although previous studies have focused on $\alpha-2$ agonist reduction of catecholamine release (Murphy et al., 1996b), the present data suggest that $\alpha-2$ agonists may also protect PFC cognitive functions by inhibiting activation of the PKA pathway. More research is needed to determine whether intra-PFC inf usions of specific PKA inhibitors can prevent stressinduced working memory deficits. Additional research is also needed to observe whether PKA activation in the PFC, like exposure to stress, is without effect on performance of control tasks. It also will be of interest to perform biochemical studies to examine whether stress exposure activates the cAMP-PKA pathway in the PFC. However, given the inherently stressful nature of many biochemical experiments, it may require considerable effort to maintain nonstressed control subjects.

\section{Comparisons with PKA mediation of long-term memory consolidation}

The present results contrast with an extensive literature demonstrating that activation of the PKA pathway is critical for the establishment of long-term memory consolidation, particularly processes dependent on protein synthesis. Much of this work has focused on hippocampal and amygdala function, in which both electrophysiological and behavioral studies indicate that PKA activation enhances long-term memory consolidation (Abel et al., 1997; Bernabeu et al., 1997; Barad et al., 1998; Bourtchouladze et al., 1998, Huang et al., 1998). Activation of the PKA pathway appears important for learning and memory consolidation across many species, including Drosophila (Yin et al., 1994), Aplysia (Dash et al., 1990), and crab Chasmagnathus (Romano et al., 1996), as well as rodents (Frey et al., 1993; Bourtchouladze et al., 1994; Weisskopf et al., 1994). Thus, it is striking to observe opposite effects of activating PKA on working memory function in the current study. However, if one considers that working memory requires the continuous updating of memory buffers, whereas long-term memory consolidation involves static changes, these opposite effects should not be unexpected. Given the importance of intracellular signaling mechanisms to long-term memory consolidation, pharmaceutical companies are developing agents that enhance the activity of PKA and related pathways as potential cognitive enhancers for human memory disorders. The results from the current study caution that mechanisms leading to "cognitive enhancement" are not universal. Thus, efforts to produce agents that would activate the PKA pathway might enhance long-term memory consolidation but might impair the ability to use working memory to flexibly and effectively guide behavior. 


\section{REFERENCES}

Abel T, Nguyen PV, Barad M, Deuel TA, Kandel ER, Bourtchouladze R (1997) Genetic demonstration of a role for PKA in the late phase of LTP and in hippocampus-based long-term memory. Cell 88:615-626.

Arnsten AFT (1998) The biology of feeling frazzled. Science 280:1711-1712.

Arnsten AFT, Goldman-Rakic PS (1998) Noise stress impairs prefrontal cortical cognitive function in monkeys: evidence for a hyperdopaminergic mechanism. Arch Gen Psychiatry 55:362-369.

Arnsten AFT, Mathew R, Ubriani R, Taylor JR, Li B-M (1999) Alpha-1 noradrenergic receptor stimulation impairs prefrontal cortical cognitive function. Biol Psychiatry 45:26-31.

Barad M, Bourtchouladze R, Winder DG, Golan H, Kandel E (1998) Rolipram, a type IV-specific phosphodiesterase inhibitor, facilitates the establishment of long-lasting long-term potentiation and improves memory. Proc Natl Acad Sci USA 95:15020-15025.

Bernabeu R, Bevilaqua L, Ardenghi P, Bromberg E, Schmitz P, Bianchin M, Izquierdo I, Medina JH (1997) Involvement of hippocampal cAMP/cAMP-dependent protein kinase signaling pathways in a late memory consolidation phase of aversively motivated learning in rats. Proc Natl Acad Sci USA 94:7041-7046.

Birnbaum SG, Arnsten AFT (1996) The alpha-2A noradrenergic agonist, guanfacine, reverses the working memory deficits induced by pharmacological stress (FG7142). Soc Neurosci Abstr 22:1126.

Bourtchouladze R, Frenguelli B, Blendy J, Cioffi D, Schultz G, Silva AJ (1994) Deficient long-term memory in mice with a targeted mutation of the cAMP-responsive element-binding protein. Cell 79:59-68.

Bourtchouladze R, Abel T, Berman N, Gordon R, Lapidus K, Kandel E (1998) Different training procedures recruit either one or two critical periods for contextual memory consolidation, each of which requires protein synthesis and PKA. Learn Mem 5:365-374.

Brito GNO, Thomas GJ, Davis BJ, Gingold SI (1982) Prelimbic cortex, mediodorsal thalamus, septum and delayed alternation in rats. Exp Brain Res 46:52-58.

Bubser M, Schmidt W (1990) 6-OHDA lesions of the rat prefrontal cortex increases locomotor activity, impairs acquisition of delayed alternation tasks, but does not affect uninterupted tasks in the radial maze. Behav Brain Res 37:157-168.

Dash PK, Hochner B, Kandel ER (1990) Injection of the cAMPresponsive element into the nucleus of Aplysia sensory neurons blocks long-term facilitation. Nature 345:718-721.

Duman RS, Nestler EJ (1995) Signal transduction pathways for catecholamine receptors. In: Psychopharmacology: the fourth generation of progress (Bloom FE, Kupfer DJ, eds), pp 303-320. New York: Raven.

Finn JT, Grunwald ME, Yau K-W (1996) Cyclic nucleotide-gated ion channels: an extended family with diverse function. Annu Rev Physiol 58:395-426.

Frey U, Huang Y-Y, Kandel ER (1993) Effects of cAMP simulate a late stage of LTP in hippocampal CA1 neurons. Science 260:1661-1664.

Goldman-Rakic PS (1987) Circuitry of the primate prefrontal cortex and the regulation of behavior by representational memory. In: Handbook of physiology, the nervous system, higher functions of the brain (Plum F, ed), pp 373-417. Bethesda, MD: American Physiological Society.

Huang Y-Y, Kandel ER (1998) Post-synaptic induction of PKAdependent expression of LTP in the lateral amygdala. Neuron 21:169-178.
Kesner RP, Farnsworth G, DiMattia BV (1989) Double dissociation of egocentric and allocentric space following medial prefrontal and parietal cortex lesions in the rat. Behav Neurosci 103:956-961.

Kolb B (1990) Prefrontal cortex. In: The cerebral cortex of the rat (Kolb B, Tees RC, eds), pp 437-458. Cambridge, MA: MIT.

Larsen JK, Divac I (1978) Selective ablations within the prefrontal cortex of the rat and performance of delayed alternation. Physiol Psychol 6:15-17.

Mishkin M (1964) Perseveration of central sets after frontal lesions in monkeys. In: The frontal granular cortex and behavior (Warren JM, Akert K, eds), pp 219-241. New York: McGraw-Hill.

Murphy BL, Arnsten AFT, Goldman-Rakic PS, Roth RH (1996a) Increased dopamine turnover in the prefrontal cortex impairs spatial working memory performance in rats and monkeys. Proc Natl Acad Sci USA 93:1325-1329.

Murphy BL, Arnsten AFT, Jentsch JD, Roth RH (1996b) Dopamine and spatial working memory in rats and monkeys: Pharmacological reversal of stress-induced impairment. J Neurosci 16:7768-7775.

Punch LJ, Self DW, Nestler EJ, Taylor JR (1997) Opposite modulation of opiate withdrawal behaviors on microinfusion of protein kinase A inhibitor versus activator into the locus coeruleus or periaqueductal gray. J Neurosci 17:8520-8527.

Romano A, Locatelli F, Delorenzi A, Pedreira ME, Maldonado H (1996) Effects of activation and inhibition of cAMP-dependent protein kinase on long term habituation in the crab Chasmagnathus. Brain Res 735:131-140.

Self DW, Genova LM, Hope BT, Barnhart WJ, Spencer JJ, Nestler EJ (1998) Involvement of cAMP-dependent protein kinase in the nucleus accumbens in cocaine self-administration and relapse of cocaineseeking behavior. J Neurosci 18:1848-1859.

Squire LR, Zola-Morgan S (1991) The medial temporal lobe memory system. Science 253:1380-1386.

Surmeier DJ, Bargas J, Hemmings HCJ, Nairn AC, Greenguard P (1995) Modulation of calcium currents by a D1 dopaminergic protein kinase/ phosphatase cascade in rat neostriatal neurons. Neuron 14:385-397.

Van Haastert PJM, Van Driel R, Jastorff B, Baraniak J, Stec WJ, De Wit RJW (1984) Competitive cAMP antagonists for cAMP-receptor proteins. J Biol Chem 259:10020-10024.

Weisskopf MG, Castillo PE, Zalutky RA, Nicoll RA (1994) Mediation of hippocampal mossy fiber long-term potentiation by cyclic AMP. Science 265:1878-1882.

Williams GV, Goldman-Rakic PS (1995) Blockade of dopamine D1 receptors enhances memory fields of prefrontal neurons in primate cerebral cortex. Nature 376:572-575.

Yang CR, Seamans JK (1996) Dopamine D1 receptor actions in layers V-VI rat prefrontal cortex neurons in vitro: modulation if dendriticsomatic signal integration. J Neurosci 16:1922-1935.

Yin JCP, Wallach JS, Del Vecchio M, Wilder EL, Zhou H, Quinn WG, Tully T (1994) Induction of a dominant negative CREB transgene specifically blocks long-term memory in Drosophila. Cell 79:49-58.

Zahrt J, Taylor JR, Mathew RG, Arnsten AFT (1997) Supranormal stimulation of dopamine D1 receptors in the rodent prefrontal cortex impairs spatial working memory performance. J Neurosci 17:85288535 . 